\title{
Competing Communications Networks and International Trade
}

\author{
Marcelo Fukushima \\ Kobe University \\ Toru Kikuchi \\ Kobe University
}

\begin{abstract}
This paper investigates the effects of competing communication networks on trade patterns in a Chamberlinian-Ricardian model of monopolistically competitive firms with a continuum of industries that require communication services in production. We conclude that intraindustry trade between different networks is determined by the relative size of networks and technological differences, and that a network will not have an incentive to expand indefinitely, despite network externalities.
\end{abstract}

- JEL classification: D43, F12

- Keywords: Competing communications networks, International trade

\section{Introduction}

As globalization accelerates, countries and regions are increasingly integrated into economic zones that function under similar international business and technological environments. The increase in trade and the spread of international production networks are seen as important causes behind the standardization of

\footnotetext{
*Corresponding address: Marcelo Fukushima, Graduate School of Economics, Kobe University, 1-1215-103 Fukae Honmachi, Higashi Nada-ku, Kobe-shi, 658-0021, Japan; Tel: +81-90-8376-1970, Email: 047D257E@stu.kobe-u.ac.jp, Toru Kikuchi, Graduate School of Economics, Kobe University 21 Rokkodai-cho, Nada-ku, Kobe-shi, 657-8501, Japan; E-mail: kikuchi@econ.kobe-u.ac.jp. 
such environments, and it is possible to identify two major players in the scene: multinational firms and communications networks. Multinational firms very often replicate headquarter technologies or business practices in their foreign subsidiaries - therefore allowing for the diffusion of technology - whereas communications infrastructures link remote markets and firms, enabling trade. Both deal with the intense exchange of information, specifications and know-how, as well as with coordination of services across national and international markets and, consequently, benefit from developments in technologies that eliminate communication barriers.

In this context, decreasing communications costs may represent an important factor in the formation of production networks and economic zones. Firms may benefit from the lower costs incurred in the coordination of activities and expand production over many countries. ASEAN in Southeast Asia is an example of an economic zone in which Japanese companies have developed extensive production networks that require business coordination, similar to the case for American companies in NAFTA. Different economic zones, however, may be part of different production networks due to a variety of reasons such as language, proximity, infrastructure, market regulation, etc as pointed out by Kikuchi (2005).

The importance of technology in the determination of trade patterns has long being a concern of classical trade models of perfect competition and of more recent models featuring increasing returns and imperfect competition. ${ }^{1}$ Technology transfers in a Ricardian framework have important implications for trade patterns and welfare as Jones and Ruffin (2006) argue. They show that countries may benefit by transferring even their best technology provided there is an increase in relative wages. In the increasing-returns framework, Venables (1999) analyzes the interaction between Ricardian technologies and agglomeration forces showing that trade patterns may have different outcomes from those predicted by comparative advantage. Kikuchi et al. (2006) explored the role of cross-country technical heterogeneity in a multisectoral two-country model, showing that the inclusion of Ricardian technical differences brings about the agglomeration of the manufacturing sector in one country and makes intraindustry trade unlikely unless there is technical equalization in some industries.

This paper extends the analysis conducted by Kikuchi et al. (2006) by incorporating a multi-country framework with competing international communications

\footnotetext{
${ }^{1}$ See Krugman (1979).
} 
networks. As in Kikuchi et al. (2006), the model assumes Chamberlinian-Ricardian monopolistic competition with a continuum of industries in a Dornbusch, Fischer, and Samuelson (1977) fashion. Networks externalities, as in Harris $(1995,2001)$, are added to the model and represent the main factor determining cross-country differences in technology. It will be demonstrated that the relative size of the networks determines the equilibrium specialization pattern, which can change dramatically with even a small variation in relative network size. Also, it will be shown that, at a certain point, the expanding monopolist network may block newcomers to avoid a fall in relative wages. ${ }^{2}$ This paper goes beyond the existing literature to show how trade patterns can be determined in the presence of network externalities as the main reason behind technology standardization across countries.

The next section develops a Chamberlinian-Ricardian model with a continuum of industries and competing international communications networks. Section 3 deals with the determinants of trade patterns. Section 4 concludes the analysis.

\section{The Model}

Consider a world economy consisting of a finite number of countries $N$. Suppose that each country is identical and endowed with $\mathrm{L}$ units of labor, which is the only primary factor of production. We assume that there is a continuum of industries with mass $[0, M]$. Manufacturing industries have size $m$ and agricultural industries have size $M-m$. Industry-specific variables will be indexed by the industry label $i$. Consumers have Cobb-Douglas preferences and purchase equal values of the output of all industries. The agricultural industries produce under constant returns to scale with one unit of labor producing one unit of a homogeneous agricultural product, which is taken as the numeraire. Moreover, we assume the technology of agricultural products to be identical for all countries. Each manufacturing industry is modeled as a Dixit-Stiglitz (1977) monopolistically competitive industry. The quantity index of manufacturing industry $i$ takes the form

$$
X^{i}=\left(\sum_{j=1}^{N} \sum_{k=1}^{n^{i j}}\left(d_{k j}^{i}\right)^{\theta}\right)^{\frac{1}{\theta}}, 0<\theta<1,
$$

\footnotetext{
${ }^{2}$ See Kikuchi (2005) for more detailed discussion on this point.
} 
where $n^{i j}$ is the number of products produced in industry $i$ in country $j, d_{k j}^{i}$ is the quantity of product $k$ of industry $i$ produced in country $j$, and $1 /(1-\theta)>1$ is the elasticity of substitution between every pair of products. The sectoral price index can be obtained as:

$$
P^{i}=\left(\sum_{j=1}^{N} \sum_{k=1}^{n^{i j}}\left(p_{k j}^{i}\right)^{\frac{\theta}{\theta-1}}\right)^{\frac{\theta-1}{\theta}},
$$

where $p_{k j}^{i}$ is the price of the $k$-th differentiated product of industry $i$ produced in country $j$. Solving the consumers' maximization problem yields the following demand function of consumers for product $k$ of industry $i$ produced in country $j$ :

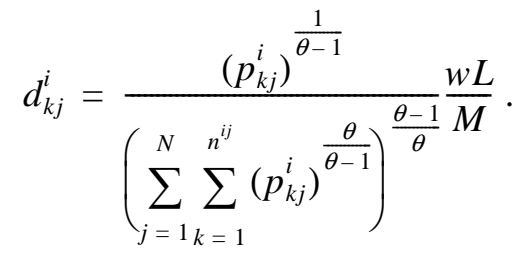

The central assumption of the model is that both the production and the distribution of differentiated products require communications activities, which are provided by a supply network. The network can be thought of as being provided by a public monopoly that employs average-cost pricing. ${ }^{3}$ Each manufacturing firm pays a fixed fee $\alpha$, which shall be referred to as communication costs, in exchange for unlimited access up to the maximum output of their particular connection.

Assume that there exists two global coordination networks, $l$ and 2, with $N_{1}$ and $\mathrm{N}_{2}$ countries each, linking the suppliers of the industry in the connected countries. ${ }^{4}$ The networks are public in that any firm can have access at some common price. They are international in scope and provide all the necessary services to operate as suppliers within manufacturing industries.

A key assumption of the model is that the pricing policy of the public communications suppliers is such that they always charge the true average cost. This is a dramatic simplification and ignores a host of issues linked to the network competition emphasized in the IO literature.

\footnotetext{
${ }^{3}$ This assumption is taken from Harris (2001).

${ }^{4}$ We assume $N=N_{1}+N_{2}$.
} 
Now, turn to the cost structure of the provider. One of the main assumptions is that there are fixed costs in the provision of the network, so that over a certain range, communication costs per user are falling. For tractability, we assume there are only fixed network provision costs, $K$, similar for both networks. Because of average-cost pricing, the communication costs per user of network 1 are simply

$$
\alpha_{1}(u)=K / u_{1}
$$

where $u$ is the number of users of the network. Note that each firm perceives communication costs as fixed costs, while the level of such costs depends on the number of users. Similarly, the communication costs per user of network 2 are $\alpha_{1}(u)=K / u_{1}$.

Each firm in the manufacturing industry $i$ in a country $j$ has both $\alpha$ units of labor as fixed input and $\beta$ units of labor as variable input. With the number of firms being very large, the elasticity of demand for each product becomes $1 /(1-\theta)$. Thus, each product $k$ is priced at a markup over marginal cost:

$$
p_{k j}^{i}=\frac{\beta^{i} w^{j}}{\theta}
$$

Note that, since firms of industry $i$ in the same country have identical variable costs, there will be symmetric prices in equilibrium. Moreover, as the fixed $\operatorname{cost} \alpha$ is divided equally among firms of member countries, firms in the same industry in countries belonging to the same network have identical fixed costs. Therefore, using the price equation (5), the summation in equation (2) takes the form

$$
\sum_{j=1}^{N} \sum_{k=1}^{n^{i j}}\left(p_{k j}^{i}\right)^{\frac{\theta}{\theta-1}}=N_{1} n_{1}^{i}\left(\frac{\beta^{i} w_{1}}{\theta}\right)^{\frac{\theta}{\theta-1}}+N_{2} n_{2}^{i}\left(\frac{\beta^{i} w_{2}}{\theta}\right)^{\frac{\theta}{\theta-1}}
$$

where $n_{1}^{i}\left(n_{2}^{i}\right)$ is the number of firms in industry $i$ in a country belonging to network $1(2)$ and $w_{1}\left(w_{2}\right)$ is the wage rate in network $l(2)$.

Substituting this into the demand function yields the profit function of each firm $k$ in industry $i$ connected to network $1:^{5}$

${ }^{5}$ Hereafter, the subscript $k$ is often dropped for simplicity. 


$$
\begin{aligned}
\pi_{1}^{i} & =\left(p_{1}^{i}-\beta^{i} w_{1}\right) x_{1}-\alpha_{1} w_{1} \\
& =\frac{1-\theta}{\theta} \beta^{i} w_{1}\left(N_{1} d_{1}^{i 1}+N_{2} d_{1}^{i 2}\right) \\
= & \frac{(1-\theta)\left(\frac{\beta^{i} w_{1}}{\theta}\right)\left(N_{1}+N_{2}\right) L}{N_{1} n_{1}\left(\frac{\beta^{i} w_{1}}{\theta}\right)^{\frac{\theta}{\theta-1}}+N_{2} n_{2}\left(\frac{\beta^{i} w_{2}}{\theta}\right)^{\frac{\theta}{\theta-1}} \frac{w_{1}+w_{2}}{M}-\alpha_{1} w_{1},}
\end{aligned}
$$

where $d_{1}^{i 1}\left(d_{1}^{i 2}\right)$ is the demand of the consumers of network 1 (2) for a product of industry $i$ produced by network 1 .

Similarly, the profit function of each firm connected to network $\$ 2 \$$ is

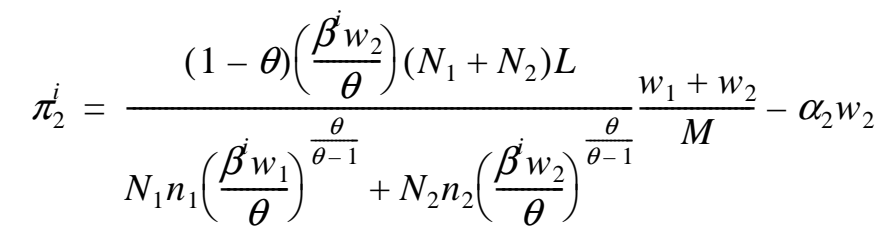

Given that there are two competing groups of countries, let us examine the specialization pattern of industry $i$.

In a trading equilibrium with zero transport costs, non-positive profits in industry $i$ in each country and network are necessary, with profits being equal to zero if production takes place. Thus, by setting profits at zero for both countries of networks 1 and $2\left(\pi_{1}^{i}=\pi_{2}^{i}=0\right)$, we would like to test whether the coexistence of firms in both networks is consistent with equilibrium.

First, let us draw attention to the condition that if firms in industry $i$ of both networks coexist, profits must be identical for each firm in both networks, i.e.,

$$
\pi_{1}^{i}=\pi_{2}^{i}
$$

This is the condition that must be satisfied if $\left(\pi_{1}^{i}=\pi_{2}^{i}=0\right)$ is to hold. Substituting (7) and (8) into (9), the following result is obtained

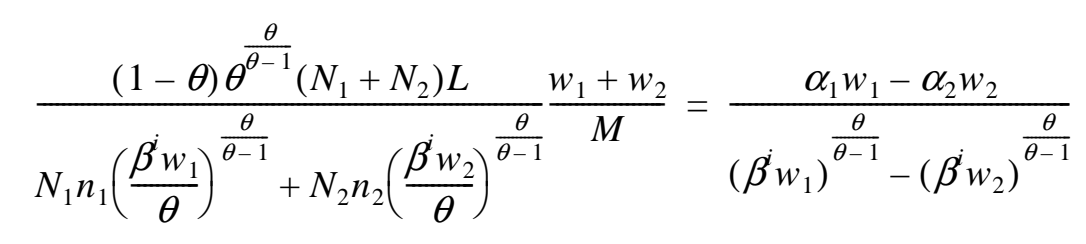


Inserting the RHS of (9) into the profit function yields

$$
\begin{aligned}
\pi_{1}^{i} & =\frac{w_{1}^{\frac{\theta}{\theta-1}}\left(\alpha_{1} w_{1}-\alpha_{2} w_{2}\right)}{w_{1}^{\frac{\theta}{\theta-1}}-w_{2}^{\frac{\theta}{\theta-1}}}-\alpha_{1} w_{1} \\
\pi_{2}^{i} & =\frac{w_{2}^{\frac{\theta}{\theta-1}}\left(\alpha_{1} w_{1}-\alpha_{2} w_{2}\right)}{w_{1}^{\frac{\theta}{\theta-1}}-w_{2}^{\frac{\theta}{\theta-1}}}-\alpha_{2} w_{2} .
\end{aligned}
$$

It is important to note that profits are independent of both the total number of firms and market size.

Before turning to the case of coexistence, note that the equilibrium number of firms

$$
\begin{aligned}
& n_{1\left[n_{2}^{i}=0\right]}^{i T}=\frac{(1-\theta)\left(w_{1}+w_{2}\right)\left(N_{1}+N_{2}\right) L}{N_{1} M \alpha_{1} w_{1}} \\
& n_{2\left[n_{2}^{i}=0\right]}^{i T}=\frac{(1-\theta)\left(w_{1}+w_{2}\right)\left(N_{1}+N_{2}\right) L}{N_{2} M \alpha_{2} w_{2}}
\end{aligned}
$$

where $T$ denotes a trading equilibrium value.

Using these results, the necessary condition for the coexistence of firms is obtained. Remembering that the manufacturing industry has length $m$ while the range of the agricultural industry $M-m$, and that agricultural industries in all countries share the same technology, let us define the technology index by

$$
A(i) \equiv \begin{cases}\left(\frac{\alpha_{2}}{\alpha_{1}}\right)^{1-\theta} & \text { for } i \in[0, m] \\ 1 & \text { for } i \in[m, M]\end{cases}
$$

Since in free-trade equilibrium profits must be zero $\left(\pi_{1}^{i}=\pi_{2}^{i}=0\right)$, simple calculations show that (10) and (11) are satisfied only if the technology index, $A$, is equal to the relative wage rate $\omega \equiv w_{1} / w_{2}$.

Proposition 1. If $\mathrm{A}(\mathrm{i})>(<) \omega$, only firms in network 1 (2) produce in the differentiated products industry i. Intraindustry trade between countries in network 1 and 2 (i.e., the co-existence of firms in industry i of networks 1 and 2) occurs 
only if $\mathrm{A}(\mathrm{i})=\omega$.

[Proof] Suppose that $A(i)>\omega$. In this case, firms of industry $i$ in both networks cannot co-exist.

It is clear that only firms of network 1 are active is an equilibrium, since

$$
\pi_{2\left[n_{1}^{i}=n_{2}^{i}=0\right]}^{i}=\left(\frac{w_{2}}{w_{1}}\right)^{\frac{\theta}{\theta-1}} \alpha_{1} w_{1}-\alpha_{2} w_{2}=\alpha_{2} w_{2}\left[\left(\frac{\omega}{A(i)}\right)^{\frac{1}{\theta-1}}-1\right] .
$$

This becomes negative if $A(i)>\omega$ since $\theta \in(0,1)$. Therefore, firms of network 2 have no incentive to enter the market given that $n_{1}^{i T}$ firms of network 1 are active. On the other hand, the case in which only firms of network 2 are active cannot support a free trade equilibrium. This is because

$$
\pi_{2\left[n_{1}^{i}=0, n_{2}^{i}=n_{2}^{i T}\right]}^{i}=\left(\frac{w_{1}}{w_{2}}\right)^{\frac{\theta}{\theta-1}} \alpha_{2} w_{2}-\alpha_{1} w_{1}=\alpha_{1} w_{1}\left[\left(\frac{A(i)}{\omega}\right)^{\frac{1}{\theta-1}}-1\right]
$$

is positive, and hence, firms of network 1 have an incentive to enter the global market. Therefore, only firms of network 1 produce differentiated products in industry $i$ in the free trade equilibrium. The case of $A(i)<\omega$ can be proven analogously. [Q.E.D.]

\section{Trade Patterns}

In order to examine trade patterns in world equilibrium, we need to consider balanced trade and technological constraints. Let $m^{\prime}$ be a hypothetical dividing line between commodities produced in countries of network 1 and 2 . The equilibrium in the market for products of a country in network 1 requires that labor income be equal to world spending on the products produced there:

$$
w_{1} L=N_{1} m^{\prime} \frac{w_{1} L}{M}+N_{2} m^{\prime} \frac{w_{2} L}{M} .
$$

This schedule is depicted in Figure 1 as the upward sloping locus $O B$ and is obtained by rewriting the above equation in the form 
Figure 1. Trade Equilibrium with Symmetric Networks

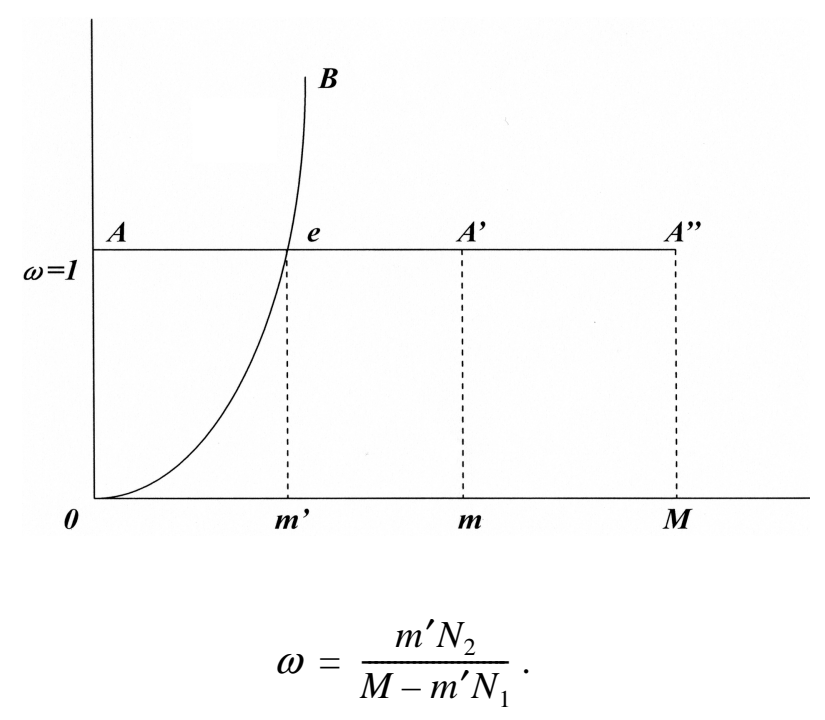

Figure 1 denotes the case of symmetric networks, that is, networks with the same number of countries $\left(N_{1}=N_{2}\right)$. In this case, the same number of countries implies the same number of firms in each industry and the same number of users in each network and country $\left(n_{1}^{i}=n_{2}^{i}\right.$ and $\left.u_{1}=u_{2}\right)$.

This results in the equalization of fixed costs of manufacturing industries across countries. Therefore, the technology index $A(i)$ is 1 for all industries. This schedule is depicted in Figure 1 as the horizontal locus $A A$ ". The equilibrium relative wage, then, is obtained at point $e$, the intersection between schedules $A A^{\prime \prime}$ and $0 \mathrm{~B}$. As a result, all countries become completely identical trading differentiated products only.

Proposition 2. With networks symmetric in size, technologies in the manufacturing sector are equalized over countries and over networks. Then, only intraindustry trade of differentiated products will occur between countries in the same network and between countries of different networks, with each country producing the homogeneous good in an equal amount.

Next, we examine what happens when a country moves from one network to another. More specifically, suppose a country quits network 2 and joins network 1 . This immediately reduces the number of users of network 2 and increases the number of users of network 1 , shifting up the technology schedule $A A^{\prime}$ as shown in Figure 2. Note that the technology schedule for the agricultural index does not change.

From (13), we see that the trade-balance condition also changes according to the 
Figure 2. Change in Relative Network Size and Trade Pattern

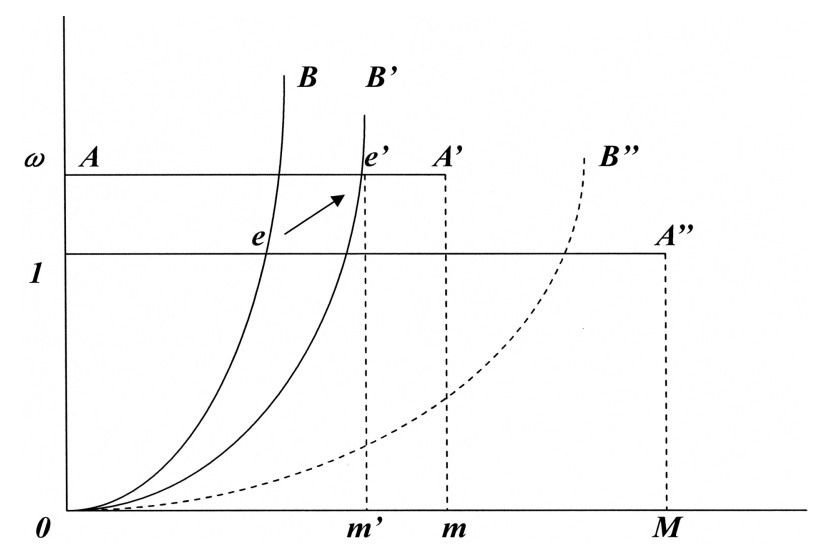

relative size of the networks. An increase in the number of countries in network 1 moves the trade-balance schedule rightward as depicted by $O B^{\prime}$, changing the intersection point from $e$ to $e^{\prime}$. In this case, the relative wage $\omega$ increases and countries in network 1 specialize in the production of differentiated products, causing interindustry trade to occur.

Remark. Even a small variation in the relative size of the networks may change trade patterns dramatically.

Note that countries will have an incentive to join network 1 provided the equilibrium relative wage continues to increase. Considering $N=N_{1}=N_{2}$, clearly, the technology schedule $A A^{\prime}$ will always shift upward if the relative size of network 1 increases. If the variation in the number of countries is small relative to the total number, the trade balance condition (13) will change according to

$$
\frac{\partial \omega}{\partial N_{1}}=\frac{m^{\prime}\left(m^{\prime} N-M\right)}{\left(M-m^{\prime} N_{1}\right)^{2}}
$$

Thus, if $m^{\prime}<M / N$, that is, if the number of industries is large enough relative to the number of countries, the schedule $O B^{\prime}$ will always move rightward and, based on the relative wage, network 1 will have an incentive to expand only up to the point where $m^{\prime}=m$. Put another way, network $l$ does not have an incentive to grow indefinitely since the trade balance condition will require countries in network 1 to produce in a greater range of industries (as in schedule $O B^{\prime \prime}$ in Figure 2). ${ }^{6}$

${ }^{6}$ Note that if $m^{\prime}>M / N$ always holds, network 1 has the incentive to grow indefinitely, which is not likely. 
Proposition 3. Suppose countries in Network 1 produce the manufacturing product and all countries in the world belong to either network $\left(N=N_{1}=N_{2}\right)$. Then, if $\mathrm{m}^{\prime}<\mathrm{M} / \mathrm{N}$, network 1 has an incentive to expand based on higher relative wages only up to the point where $\mathrm{m}^{\prime}=\mathrm{m}$ in equilibrium.

Notice that if $m^{\prime}$ is strictly larger than $m$ after the expansion, the relative wage rate drops to 1 , suggesting that the monopolist network would be willing to stop the process of expansion. To illustrate this, think of the network as consisting of a group of developed countries producing the differentiated product. A non-member developing country has an interest in acquiring new technology and raising its relative wage, thus it is willing to join the network. If, however, the developing country joins the network, this would cause a sudden drop in the relative wage the case where the post-expansion $m^{\prime}$ exceeds $m$. Then, the developed countries would not accept the new member in the network based on the relative wage (or terms of trade) argument. ${ }^{7}$

It is noteworthy that possible modifications of the model can be made by, for example, endogenizing the size of the manufacturing and agricultural industries or allowing for differences in variable costs across industries endogenizing the size of the comprising portion of industries of the network. In the first case, the technology schedule would not only shift upward or downward with a change in relative size, but it would also contract or expand in length. In the second case, the flat segment would be limited to a portion of the manufacturing industries.

\section{Conclusion}

A multi-country Chamberlinian-Ricardian trade model was built assuming monopolistic competition, a continuum of goods, and production requiring communications services. Moreover, communication services are subject to network externalities and are provided by two communications networks. All countries belong to one of the two networks. The provision of communications services incurs a fixed cost that is equally shared by users, thus the greater the number of users, the smaller the fixed cost faced by each network member.

The main conclusions are the following: intraindustry trade between different networks will happen only if there is equalization between the relative wage and the technology index of manufacturing industries; when networks are of equal size,

${ }^{7}$ See Kikuchi (2005). 
only intraindustry trade will occur between networks; and, with a large number of industries relative to the number of countries, a network will not have an incentive to expand indefinitely, despite network externalities, since an exceedingly large number of member countries may cause the relative wage to drop.

The following situation illustrates the intuition behind our main result. Suppose there are two symmetrical networks in the world that compete in the production of a differentiated good that requires communication services - for instance, electronic goods. Initially countries in both networks also produce an agricultural good. Now suppose one country leaves a network and joins another. In that case, the enlarged network will have lower communication costs - since the total fixed costs are split among a larger number of countries - and comparative advantage in the electronic industries. As a result, countries in the enlarged network will produce and export only electronic goods and import the agricultural good, while countries in the reduced network will produce and export both electronic and agricultural goods. There will be intraindustry trade of electronics between networks and countries will have an incentive to enter the enlarged network in order to enjoy better terms of trade. As more and more countries stop producing agricultural goods to specialize in the production of electronics, at a certain point, a further enlargement of the network may force the terms of trade to drop in order to meet the condition of balanced trade. If that happened, countries of the larger network would start producing agricultural goods again (and keep producing electronics), and countries in the smaller network would now produce only agricultural goods. Thus it is expected that the network stop growing right before that happens.

\section{Acknowledgements}

We wish to thank the anonymous referee for the very constructive comments that helped to improve the paper. Also, we would like to thank Tetsuro Ichikawa, Jota Ishikawa, Noritsugu Nakanishi and the participants of the Rokko Forum at Kobe University for their insightful comments on an earlier version of the paper. Any errors are the responsibility of the authors.

Received 5 February 2007, Accepted 29 October 2007 


\section{References}

Dixit, A. K., and Stiglitz, J. E. (1977) Monopolistic Competition and Optimum Product Diversity, American Economic Review, 67, 297-308.

Dornbusch, R., Fischer, S., and Samuelson, P. (1977) Comparative Advantage, Trade and Payments in a Ricardian Model with a Continuum of Goods, American Economic Review, 67, 823-29.

Harris, R. G. (1995) Trade and Communication Costs, Canadian Journal of Economics, 28, 46-75.

Harris, R. G. (2001) Trade and Communication Costs, in Arndt, S. W. and Kierszkowski, H. (eds.), Fragmentation: New Production Patterns in the World Economy, New York: Oxford University Press.

Jones, R. W., and Ruffin, R. J. (2006) The Technology Transfer Paradox, mimeo.

Kikuchi, T. (2005) On the enlargement of interconnected communications networks in the world economy, The Quarterly Review of Economics and Finance, 45, 18-27.

Kikuchi, T., Shimomura, K., and Zeng, D.-Z. (2006) On the Emergence of Intraindustry Trade, Journal of Economics, 87, 15-28.

Krugman, P. (1979) Increasing Returns, Monopolistic Competition, and International Trade, Journal of International Economics, 9, 469-79.

Venables, A. J. (1999) The International Division of Industries: Clustering and Comparative Advantage in a Multi-industry Model, Scandinavian Journal of Economics, 101, 495-513. 